\title{
Causas e impactos de la deportación de migrantes centroamericanos de Estados Unidos a México
}

\section{Causes and impacts of the deportation of Central American immigrants from the United States to Mexico}

\author{
Simón Pedro Izcara Palacios* y Karla Lorena Andrade Rubio*
}

Resumen

Durante la última década el número de migrantes expulsados con una orden de deportación de Estados Unidos a México casi se ha duplicado. No todos los migrantes deportados a México tienen nacionalidad mexicana, algunos son ciudadanos de países centroamericanos. Este artículo, fundamentado en una metodología cualitativa que incluye entrevistas en profundidad a 75 migrantes centroamericanos que fueron deportados de los Estados Unidos, analiza las causas y el efecto de la deportación de inmigrantes centroamericanos de Estados Unidos a México y concluye que estas deportaciones pueden conducir a un incremento de la violencia en México.

Palabras clave: deportación, migrantes indocumentados, Centroamérica, Estados Unidos, Tamaulipas.

Recibido: 20 de octubre de 2013.

Aceptado: 2 de octubre de 2014.
Abstract

Over the last decade, the number of immigrants deported from the United States to Mexico based on an order of removal has nearly doubled. Not all migrants removed to Mexico are Mexican citizens, some are Central America citizens. This article, usins qualitative methods that includes in-depth interviews with 75 Central American migrants who were deported from the United States, examines the causes and impacts of the deportation of Central American immigrants from United States to Mexico and concludes that these deportations led to increase in violence in Mexico.

Keywords: deportation, undocumented immigrants, Central America, United States, Tamaulipas.

* Universidad Autónoma de Tamaulipas. Unidad Académica Multidisciplinaria de Ciencias, Educación y Humanidades. Dirección: Centro Universitario “Adolfo López Mateos”. R.P. No 476, C.P. 87149, Ciudad Victoria, Tamaulipas, México. Correo electrónico: sizcara@uat.edu.mx,kandrade@uat.edu.mx 
Simón P. Izcara y Karla L. Andrade / Causas e impacto de la deportación de migrantes centroamericanos

\section{Introducción}

Entre los años 2000 y 2011, el número de migrantes expulsados con una orden de deportación desde Estados Unidos hasta México creció 95\%, pasando de 150644 a 293966 personas (Department of Homeland Security, 2011). Pero no todos los migrantes indocumentados expulsados a México tienen nacionalidad mexicana; algunos proceden de Centroamérica.

El incremento de las deportaciones en la última década obedece a una recodificación de las violaciones civiles en actos criminales, que eleva de manera importante el riesgo de la población migrante de ser removida de los Estados Unidos, ya que entre los expulsados, cada vez predominan más los migrantes que no han cometido actos criminales (Hagan, Rodríguez y Castro, 2011, p. 1392). Los migrantes centroamericanos participantes en esta investigación fueron deportados de Estados Unidos principalmente por utilizar documentos apócrifos, por delitos de tráfico, por redadas en los lugares de trabajo y por deambular en las calles; otros, fueron removidos por posesión o tráfico de sustancias ilícitas y por conductas violentas, y algunos más debido a denuncias de sus empleadores. En diversos casos los migrantes residentes se entregan a las autoridades migratorias y solicitan la repatriación voluntaria. Esto se produce cuando el migrante debe retornar precipitadamente a su país debido a una urgencia familiar: la enfermedad o el fallecimiento de un pariente cercano.

La deportación de inmigrantes centroamericanos de Estados Unidos a México es un fenómeno importante sobre el cual no hay datos estadísticos. Ni las autoridades migratorias estadunidenses ni las mexicanas reconocen que se estén deportando personas foráneas a México; sin embargo, la existencia de este fenómeno se ha tornado vox populi. Para los residentes de las ciudades fronterizas no todos los migrantes deportados son ciudadanos mexicanos; asimismo, una gran cantidad de migrantes centroamericanos refieren que algunos de sus compatriotas son removidos a México y no a sus lugares de origen. La expulsión de personas de Centroamérica (carentes de recursos económicos) a ciudades fronterizas violentas, donde no pueden acceder a ningún tipo de capital social, coloca a los migrantes en una situación vulnerable, de la cual saca partido la delincuencia organizada. 
Este artículo, fundamentado en una metodología cualitativa, analiza las causas de la deportación de inmigrantes centroamericanos desde Estados Unidos a México y examina cómo estas deportaciones conducen a un incremento de la violencia en México. En primer lugar, se presenta la metodología utilizada; a continuación, se estudia la política migratoria estadunidense de deportaciones masivas; más adelante, se analizan las causas de la remoción de inmigrantes centroamericanos a México; después, se examinan sus repercusiones y, finalmente, se describe el caso de Javier, un migrante secuestrado por la delincuencia organizada después de pagar un soborno para ser removido a México.

\section{Metodología y descripción de la muestra}

Debido al carácter exploratorio de la temática estudiada, sobre la cual no hay datos ni reconocimiento oficial, esta investigación se cimentó en un enfoque metodológico cualitativo. Este método permite acercarse a aquellos procesos difíciles de abordar a través de la aplicación de encuestas y cuestionarios, porque no son susceptibles de ser medidos en términos de frecuencia.

La técnica utilizada para el acopio de información fue la entrevista en profundidad. Por otra parte, el procedimiento de muestreo en la investigación cualitativa tiene un carácter intencional porque la selección de los participantes se fundamenta en el conocimiento y la aptitud de éstos para informar sobre el objeto de estudio. Se seleccionó tanto a migrantes centroamericanos deportados desde Estados Unidos a México, como a migrantes deportados hasta sus países de origen pero que tenían algún conocimiento sobre la deportación de personas foráneas a México.

Entre los meses de mayo de 2011 y mayo de 2013 fueron entrevistados 75 migrantes de Centroamérica (45 hombres y 30 mujeres), que después de haber sido deportados de Estados Unidos se encontraban varados en diferentes puntos de la geografía mexicana con intención de retornar a ese país.

Los entrevistados eran originarios de Guatemala, Honduras y El Salvador. $71 \%$ de los varones eran guatemaltecos, $13 \%$ procedía de El Salvador, $13 \%$ eran hondureños y uno procedía de Nicaragua. Por otra parte, 90\% de las mujeres eran guatemaltecas y 10\% salvadoreñas (cuadro 1). 
Cuadro 1. País de procedencia de los entrevistados

\begin{tabular}{|clrr|}
\hline \multirow{4}{*}{ Hombres } & $n$ & $\%$ \\
\hline & Guatemala & 32 & 71.1 \\
& El Salvador & 6 & 13.3 \\
& Honduras & 6 & 13.3 \\
& Nicaragua & 1 & 2.2 \\
& Total & 45 & 100 \\
\hline \multirow{3}{*}{ Mujeres } & Guatemala & 27 & 90 \\
& El Salvador & 3 & 10 \\
& Total & 30 & 100 \\
\hline
\end{tabular}

Fuente: Elaboración propia.

La mayor parte de los entrevistados (51\% de los varones y $97 \%$ de las mujeres) fueron deportados hasta sus países de origen; aunque $49 \%$ de los varones y $3 \%$ de las mujeres fueron deportadas hasta una ciudad fronteriza mexicana (cuadro 2).

Por otra parte, el proceso de recopilación de información se encontró sustentado por la riqueza heurística de la producción discursiva recabada. Cuando el número de discursos obtenidos permitió interpretar, explicar y describir de forma satisfactoria todas las dimensiones del objeto de estudio, se dio por concluido el trabajo de campo.

La investigación cualitativa no permite la generalización en términos de error estadísticamente cuantificable, porque no se sustenta en muestras probabilísticas. Pero el carácter ideográfico de la investigación cualitativa no significa que los resultados que produce no sean anecdóticos y no puedan ser extrapolables. La investigación cualitativa no posibilita alcanzar generalizaciones nomotéticas, pero sí permite la transferibilidad de un contexto a otro (Shaw, 2003, p. 104). En este estudio las estrategias utilizadas para incrementar la transferibilidad de los resultados obtenidos fueron dos: 1) la selección de diferentes locaciones del territorio mexicano, y 2) la búsqueda de áreas representativas de las rutas seguidas por los (transmigrantes) centroamericanos para llegar a Estados Unidos (Izcara, 2014, p. 119).

En relación con la primera estrategia, el trabajo de campo fue realizado en Abasolo, El Mante, Guémez, Hidalgo, Matamoros, Padilla, Reynosa, San Carlos, San Fernando, San Nicolás, Tampico y Victoria (Tamaulipas); Tijuana (Baja California), Monterrey (Nuevo León), México Distrito 


\section{Cuadro 2. Lugar por donde fueron deportados los entrevistados}

\begin{tabular}{|c|c|c|c|c|}
\hline & & & $n$ & $\%$ \\
\hline \multirow{11}{*}{ Varones } & \multirow{4}{*}{ Tamaulipas } & Matamoros & 6 & 13.3 \\
\hline & & Reynosa & 6 & 13.3 \\
\hline & & Nuevo Laredo & 4 & 8.9 \\
\hline & & Total & 16 & 35.5 \\
\hline & \multirow{3}{*}{ Coahuila } & Piedras Negras & 2 & 4.5 \\
\hline & & Ciudad Acuña & 1 & 2.2 \\
\hline & & Total & 3 & 6.7 \\
\hline & Chihuahua & Ciudad Juárez & 2 & 4.5 \\
\hline & Baja California & Tijuana & 1 & 2.2 \\
\hline & País de residencia & & 23 & 51.1 \\
\hline & Total & & 45 & 100 \\
\hline \multirow{3}{*}{ Mujeres } & Tamaulipas & Nuevo Laredo & 1 & 3.3 \\
\hline & País de residencia & & 29 & 96.7 \\
\hline & Total & & 30 & 100 \\
\hline \multicolumn{3}{|c|}{ Total } & 75 & 100 \\
\hline
\end{tabular}

Fuente: Elaboración propia.

Federal, Tultitlán (Estado de México), Tuxtla Gutiérrez y Arriaga (Chiapas) y San Luis Potosí.

En relación con la segunda estrategia, en Tamaulipas se realizó una parte importante del trabajo de campo porque este lugar constituye el principal punto de entrada de migrantes centroamericanos a Estados Unidos, pues aquí es donde finaliza la ruta más corta y rápida. México D. F. y el Estado de México fueron escogidos porque aquí convergen las principales rutas utilizadas por los migrantes centroamericanos para llegar a Estados Unidos. También se realizaron entrevistas en Chiapas porque esa entidad constituye el punto de entrada a México de los migrantes centroamericanos. San Luis Potosí fue seleccionado porque constituye un punto de descanso dentro de la ruta para llegar a los sectores de Laredo y Río Grande, que es donde se registra el mayor número de aprehensiones de migrantes indocumentados no mexicanos. Nuevo León también se seleccionó porque después de 2010 algunas rutas utilizadas por los centroamericanos se desviaron hacia este estado, que es menos violento que 
Tamaulipas. Finalmente, se seleccionó Baja California porque este estado suma el mayor número de deportaciones. Otras áreas fronterizas, como Ciudad Juárez, no fueron seleccionadas porque a partir de 2010 se frenaron las deportaciones por este punto.

Por lo tanto, el objetivo perseguido al seleccionar diferentes locaciones no fue establecer diferencias entre las mismas, ya que el carácter intencional de la muestra y su reducido tamaño no lo permiten, sino dilatar la amplitud de la investigación con el objetivo de lograr incrementar la transferibilidad de los resultados de este estudio.

\section{La política de deportaciones masivas}

Hasta el último cuarto del siglo xix Estados Unidos estimuló la inmigración no cualificada, categorizada como valiosa, productiva y socialmente deseable. En 1882 y 1907 se restringió la inmigración procedente de China y Japón, y las leyes de Inmigración de 1921 y 1924 establecieron un sistema de cuotas para frenar la migración del sur y este de Europa. Pero la política de deportaciones masivas no se inició hasta la Gran Depresión, cuando fueron repatriados 400000 mexicanos; asimismo, en 1954 fueron removidos más de un millón de migrantes mexicanos (Hagan et al., 2011, p. 1374). A los inmigrantes les fueron exigidos estándares conductuales superiores a los demandados al resto de la población. Aberson (1974, p. 82) criticaba la Ley de Inmigración y Naturalización de 1952 porque amenazaba con la deportación a aquellos inmigrantes que no mostrasen la moral sexual propia de finales del siglo xix y las opiniones políticas propias de inicios del siglo xix. Sin embargo, la enmienda a la Ley de Inmigración y Nacionalidad de 1965, bajo la influencia del Movimiento Afro-Americano de Derechos Civiles, subrayó los principios de la integración familiar, humanitarismo, integración social y derechos de los migrantes (King y Smith, 2005).

A partir de la segunda mitad de los años noventa, en un entorno de crecimiento de las actitudes antiinmigrante y preocupación por la seguridad nacional, se inició el actual periodo de deportaciones masivas, que se distingue de los anteriores por su duración y por el crecimiento progresivo y sostenido de las expulsiones con una orden de remoción. Estados 
Unidos adoptó una estrategia basada en la "prevención por medio de la disuasión”, que consistió en un reforzamiento del control fronterizo con más patrulleros, con la construcción de más muros y bardas, y con la adquisición de tecnología militar para detectar y detener el flujo de migrantes. Esta estrategia se concentró en los cuatro segmentos de la frontera más poblados y de mayor movimiento de migrantes. Asimismo, la Ley de Reforma de la Inmigración Ilegal y Responsabilidad de los Inmigrantes de 1996 (IIRIRA, por sus siglas en inglés), la Ley Antiterrorista y de Pena de Muerte Efectiva de 1996 (AEDPA, por sus siglas en inglés) y la Ley Patriota de 2001, expandieron los poderes del gobierno federal y las policías locales para arrestar, detener y deportar a los inmigrantes, y ampliaron las ofensas por las cuales éstos podían ser deportados.

Como consecuencia, los inmigrantes fueron percibidos como potenciales amenazas para la seguridad nacional (Brabeck, Lykes y Hershberg, 2011, p. 279; Casillas, 201, p. 299; Hagan et al., 2011, p. 1376). Antes de 1996 no era inusual la cancelación de una deportación si ésta amenazaba la estabilidad de la familia del deportado; después de la IIRIRA esta situación se tornó excepcional (Hagan, Castro y Rodríguez, 2010, p. 1804). La IIRIRA contribuyó de modo notable a la criminalización de los inmigrantes al reclasificar ofensas de carácter menor como delitos graves (Escobar, 2011, p. 78); asimismo, incrementó el número de deportaciones debido a la introducción de dos mecanismos: I) la deportación de inmigrantes legales que cometieron un delito, tras cumplir su sentencia, y II) el Programa $287(\mathrm{~g})$, que permitió a la policía local, a través de acuerdos con el Servicio de Inmigración y Aduanas (ICE, por sus siglas en inglés), detener a inmigrantes irregulares (Menjívar y Abrego, 2012, p. 1394). La AEDPA agilizó las deportaciones removiendo las barreras legales que protegían a los inmigrantes de ser deportados, y la Ley Patriota fortaleció los poderes administrativos para detener y deportar a aquellos migrantes percibidos como una amenaza para la seguridad nacional (Hagan, Esbach y Rodríguez 2008, p. 65).

Por otra parte, con objetivo de incrementar los costos de la inmigración irregular y erosionar el capital social de los migrantes, una década después se implementó la estrategia de "cumplimiento con consecuencias": con el objetivo se pretendía desincentivar el reingreso de los migrantes a Estados Unidos a partir de aprehensiones y deportaciones que 
impedían o dificultaban el acceso de éstos a su capital social. Esta estrategia se basa en la recodificación de violaciones civiles en actos criminales y en la expansión de la implementación de la política migratoria desde el borde hasta el interior con la participación de las policías locales (Hagan et al., 2011, p. 1376). En los últimos años se han implementado diferentes programas $^{1}$ para maximizar y agilizar el número de deportaciones por medio de expulsiones sin derecho a audiencia o apelación; la detención de los migrantes hasta la ejecución de la orden de deportación; la imputación de violar las leyes migratorias a muchos migrantes aprehendidos en la frontera y la devolución de algunos migrantes por un puerto distante al de entrada (Rosenblum, 2012, pp. 9 y 10).

Este último elemento, las devoluciones laterales, no es nuevo en la política migratoria estadunidense, pero se ha implementado con mayor virulencia. En la década de los cuarenta la Patrulla Fronteriza designó un sistema de transporte de los migrantes hacia espacios alejados al lugar por donde cruzaron la frontera, con objeto de quebrar las redes sociales que les permitían retornar al norte. Esta práctica incrementó la vulnerabilidad de los migrantes a los ataques de grupos criminales. Como consecuencia, las mujeres, los niños y los grupos familiares fueron exentos de esta medida y finalmente se abandonó el programa debido al visible y vergonzante daño que infringía en los migrantes (Hernández, 2010, p. 135). Como contraste, el Programa de Transferencia de Extranjeros y Programa de Salida, iniciado en 2008, despoja de su capital social a las mujeres y niños que viajan con familiares, e incrementa la probabilidad de que sean violentados, porque les separa de los varones que les acompañan. Estos programas han erosionado el capital social de los migrantes y acentuado su vulnerabilidad; pero no han logrado desincentivar el reingreso en Estados Unidos. El gobierno estadunidense ha argumentado que dichos programas garantizan la seguridad de los migrantes al impedir que contacten

\footnotetext{
${ }^{1}$ Estos programas son: la Operación "Streamline" (iniciada en 2005); la Operación contra los Contrabandistas e Iniciativa sobre Seguridad (creada en 2004); el Programa de Transferencia de Extranjeros y Programa de Salida (iniciado en 2008); el Programa de Repatriación Interior (diseñado en 2004) y los Acuerdos de Cooperación en Comunidades para incrementar la Seguridad: el Programa 287(g) (creado en 1996; pero hasta 2006 no comienza a crecer); el Programa Comunidades Seguras (creado en 2008) y el Programa Nacional de Operaciones contra Fugitivos (establecido en 2003).
} 
con los coyotes que facilitaron su ingreso en Estados Unidos. Sin embargo, como ha señalado De León (2013), acrecientan la violencia sufrida por los migrantes.

El resultado de estas estrategias ha sido un incremento sostenido de las deportaciones, que, como se observa en el cuadro 3, sufren una aceleración en los años posteriores a 1996 (cuando se aprueba la IIRIRA y la AEDPA) y 2005 (cuando se implementa la estrategia de "cumplimiento con consecuencias").

La política de deportaciones masivas ha sido sostenida por un cambio en el discurso académico. Hasta los años ochenta el debate académico cuestionaba la idea de contener la migración irregular (Champlin, 2010, p. 305). Autores como Gordon (1975) o Galbraith (1979) abogaban por una política de control fronterizo menos restrictiva porque estaban tan convencidos de los beneficios de la migración irregular que no la consideraban ofensiva. Para Piore (1979), el control fronterizo carecía de sentido, pues consideraba que la migración irregular no obedecía a diferencias salariales ni a factores de expulsión o atracción, sino a prácticas de reclutamiento implementadas por los empleadores. Como contraste, en las últimas décadas la teoría económica ortodoxa apoyó la estrategia de "prevención por medio de la disuasión” al abogar por la contención de la migración irregular

Cuadro 3. Número de expulsiones con una orden de deportación (1990-2011)

\begin{tabular}{|cccccccc|}
\hline Año & Deportaciones & $\begin{array}{c}1990= \\
100\end{array}$ & $\begin{array}{c}\text { Tasa de } \\
\text { crecimiento }\end{array}$ & Año & Deportaciones & $\begin{array}{c}1990= \\
100\end{array}$ & $\begin{array}{c}\text { Tasa de } \\
\text { crecimiento }\end{array}$ \\
\hline 1990 & 30039 & 100 & -12.7 & 2001 & 189026 & 629 & 0.3 \\
1991 & 33189 & 110 & 10.5 & 2002 & 165168 & 550 & -12.6 \\
1992 & 43671 & 145 & 31.6 & 2003 & 211098 & 703 & 27.8 \\
1993 & 42542 & 142 & -2.6 & 2004 & 240665 & 801 & 14.0 \\
1994 & 45674 & 152 & 7.4 & 2005 & 246431 & 820 & 2.4 \\
1995 & 50924 & 170 & 11.5 & 2006 & 280974 & 935 & 14.0 \\
1996 & 69680 & 232 & 36.8 & 2007 & 319382 & 1063 & 13.7 \\
1997 & 114432 & 381 & 64.2 & 2008 & 359795 & 1198 & 12.7 \\
1998 & 174813 & 582 & 52.8 & 2009 & 393457 & 1310 & 9.4 \\
1999 & 183114 & 610 & 4.7 & 2010 & 385100 & 1282 & -2.1 \\
2000 & 188467 & 627 & 2.9 & 2011 & 391953 & 1305 & 1.8 \\
\hline
\end{tabular}

Fuente: Department of Homeland Security, 2011, p. 102. 
argumentando que generaba desigualdad social, deprimía los salarios y las oportunidades económicas de los trabajadores nativos menos cualificados, y generaba un coste al sistema de seguridad social (Borjas, 1994, 2003 y 2006; Chiswick, 1988). Por otra parte, la acentuación, tanto por la teoría económica heterodoxa como por la teoría sociológica, de la naturaleza social de los procesos migratorios, y la noción de que la migración internacional constituye un proceso autosostenido, bien como señala la nueva economía de la migración laboral, porque genera privación relativa en las comunidades de origen, o bien como afirma la teoría de redes migratorias, porque crea por sí misma la estructura social necesaria para sostenerla (Izcara, 2010a y 2010b), han dado alas a la estrategia de "cumplimiento con consecuencias".

El derecho internacional exige a los estados de origen facilitar y aceptar sin retrasos la devolución de sus ciudadanos, una vez verificada la nacionalidad de los mismos (Gallagher, 2010, p. 92). Sin embargo, la simplificación y aceleración de las expulsiones con una orden de deportación, promovida por las estrategias de "prevención por medio de la disuasión" y "cumplimiento con consecuencias", ha hecho que no se estén realizando de modo adecuado los procesos de verificación de la nacionalidad de los migrantes.

\section{Las causas de la remoción de inmigrantes centroamericanos a México}

La deportación siempre constituye una experiencia traumática, pero para los migrantes centroamericanos representa un evento más desgarrador que para los mexicanos, ya que encuentran más costoso y con mayores riesgos regresar al norte. Además, los últimos, cuando emigran de modo irregular, generalmente contemplan regresar al terruño, mientras que los primeros piensan menos en el retorno. Tras ser deportados algunos centroamericanos no tienen otra opción que volver a Estados Unidos porque allí residen sus familias; otros desean regresar a su antiguo trabajo para terminar de pagar una deuda, o para ahorrar el dinero suficiente para cumplir el propósito que se plantearon inicialmente: pagar la educación de los hijos, construir una vivienda o comprar tierras. Según recientes 
estudios, más de $40 \%$ de los migrantes centroamericanos deportados no se resigna a quedarse en sus países de origen, y planea volver a cruzar la frontera (Blanchard, Hamilton, Rodríguez y Yoshioka, 2011, p. 75; Wainer, 2012, p. 13).

Atravesar México es más peligroso y costoso que cruzar la frontera estadunidense; como consecuencia, algunos migrantes centroamericanos buscan que les remuevan a México en lugar de ser deportados a sus países de origen. Como decía un migrante guatemalteco: "Yo me quiero regresar a Estados Unidos, y pues, imagínese si me regresan a mi tierra, pues n’ombre, está bien difícil; pero de aquí de la frontera de México, pues está bien facilito. Es nomás buscar un buen gancho y ya pasar otra vez" (Felipe, 2012).

Una inmigrante guatemalteca deportada a su país en enero de 2012, después de una redada en un restaurante de Colorado, donde trabajaba, decía que a ella la enviaron a su país; pero no así a algunos guatemaltecos y salvadoreños que se encontraban en el mismo centro de detención; estos últimos fueron removidos a México. Ella sostenía tres hipótesis para explicar la deportación de migrantes centroamericanos a México: 1) las autoridades estadounidenses deportan grupos tan numerosos de migrantes que no investigaban adecuadamente sus nacionalidades; 2) el gobierno estadounidense deporta migrantes centroamericanos a México porque es menos costoso, o 3 ) algunos migrantes sobornaban a las autoridades estadunidenses.

[...] a mí me trajeron de Colorado a Guatemala y ahí me dejaron, yo no tuve suerte, porque a otros que también eran de Guatemala y El Salvador los mandaron a México y ahí los deportaron; éramos muchos los deportados que a lo mejor no se fijaron, o por no gastar más los dejaron allá, o a lo mejor hubo dinero (Laura, 2012).

Estas tres hipótesis: la falta de cuidado, que se refleja en la expresión "éramos muchos los deportados que a lo mejor no se fijaron"; el interés por reducir gastos, que se desprende de la frase "por no gastar más los dejaron allá"; o el pago de sobornos, que se refleja en la idea de que "a lo mejor hubo dinero", eran remarcadas en otras entrevistas a migrantes removidos hasta sus países de origen. Como contraste, cuando preguntamos 
Cuadro 4. Causa por la que fueron deportados a México los migrantes centroamericanos

\begin{tabular}{|lrr|}
\hline & $n$ & $\%$ \\
\hline No tenía papeles y mintió sobre su nacionalidad & 9 & 39.1 \\
Falta de cuidado de las autoridades estadunidenses & 8 & 34.8 \\
Poseía documentos de identidad mexicanos apócrifos & 5 & 21.8 \\
Pagó un soborno & 1 & 4.3 \\
Total & 23 & 100 \\
\hline
\end{tabular}

Fuente: Elaboración propia.

a los migrantes centroamericanos deportados a México el aspecto que más se repetía como la causa de este evento, éste era el haber mentido acerca de su nacionalidad, bien porque carecían de documentos de identidad, o bien porque poseían documentos de identidad mexicanos apócrifos (cuadro 4).

\section{La carencia de documentos de identidad}

No es fácil averiguar la nacionalidad de los migrantes irregulares porque en ocasiones su documentación es apócrifa, esto cuando cuentan con algún documento que acredite su identidad. Aunque la mayor parte de los migrantes, sobre todo las mujeres, sí informan a las autoridades sobre su verdadera identidad, por temor a una pena más severa si descubren que están mintiendo. Esto se refleja en frases como: "sí lo pensé [decirles que era mexicano]; pero no lo hice, me dio miedo porque si me preguntaban algo de México, no sabía" (Gonzalo, 2013), o "les dije la verdad, no podía mentirles porque después te hacen pruebas para ver si dijiste la verdad, y les dije la verdad" (Teodora, 2013).

Una migrante guatemalteca decía que no era posible engañar a las autoridades migratorias. Como ella afirmaba: "A los migras no los haces pendejos, ellos saben de dónde eres, esos están bien estudiados y conocen de gente" (Vicenta, 2013). Sin embargo, la mayor parte de los entrevistados señalaba que sí era posible engañarles si se cumplían dos condiciones. La primera era no haber sido detenidos con anterioridad, porque en estos casos sus datos y huellas digitales habrían sido grabados en un soporte 
electrónico que comparten todas las agencias de seguridad; la segunda condición era tener un conocimiento de alguna parte de México, o tener familiares o amigos aquí, para poder argumentar de modo coherente.

[...] Yo les dije que era de Guatemala, ni quise mentirles porque me dio miedo de que me descubrieran; ahí donde estaba había unos salvadoreños que dijeron: somos mexicanos; pero les preguntaron varias cosas y les respondieron, y los deportaron a México, y es que ellos tenían amigos mexicanos y se pusieron el nombre de los amigos (Eduardo, 2012).

Los migrantes que más se esfuerzan en mentir a las autoridades son los que proceden de países más lejanos, como Honduras o El Salvador, ya que para ellos el costo de regresar a Estados Unidos es mayor que para los guatemaltecos. Ellos presentan una mayor tendencia a argumentar que son mexicanos para evitar ser deportados hasta sus países de origen. Muchas veces dicen que proceden de una ciudad fronteriza mexicana. Ellos pueden dar más detalles de estos lugares porque es donde pasaron más tiempo esperando la oportunidad de cruzar a Estados Unidos.

[...] Dije que era de la frontera y ahí me dejaron, en la ciudad de Matamoros, de aquí de Tamaulipas (Alfredo, 2011).

[...] Les dije mentiras con tal de que no me regresaran a mi tierra, porque pues, yo quería regresarme de nuevo a Estados Unidos, y pues, esa era la única forma de mentirles, de decirles que era de México, y pues, que mi familia estaba en Ensenada, allá en el ejido Guadalupe, que fue donde trabajé (Cirilo, 2012).

[...] Les dije que era de Victoria [Tamaulipas] (Ignacio, 2013).

Sin embargo, Chiapas es el estado de México aducido con mayor frecuencia como lugar de origen de los migrantes centroamericanos. Los migrantes guatemaltecos suelen argumentar que son de Chiapas porque muchos trabajaron allí o tienen familiares en ese estado debido a los lazos histórico-culturales tan estrechos entre el territorio más meridional de México y la zona más septentrional de Guatemala. 
Simón P. Izcara y Karla L. Andrade / Causas e impacto de la deportación de migrantes centroamericanos

Yo como quiera digo pues que soy de Tapachula, y pues, en mi cartera pues traigo las fotos de mis hijos, y pues, n'ombre, les hecho un rollo y les digo que tengo a mis hijitos en Chiapas, y pues, ya con eso pues me creen los cabrones, o pues, si no pues se hacen de la vista gorda (Alberto, 2011).

[...] Yo les dije que era de Chiapas, y pos, como ahí estuve trabajando, pues, cuando me hicieron la entrevista, pos, me creyeron; les estuve contando dónde trabajaba (Isidro, 2013).

Asimismo, algunos migrantes de otros países centroamericanos también tienen familiares residiendo en esta zona del país. Como decía un migrante hondureño, "les dije que era de Chiapas porque me acordé que ahí trabajaba mi hermana” (Basilio, 2012).

\section{La falta de cuidado de las autoridades estadunidenses}

Muchos entrevistados describen a las autoridades estadunidenses como descuidadas. Ellos afirmaban que había una tendencia a asociar a todos los migrantes latinos con el hecho de proceder de México. Algunos centroamericanos, que querían ser deportados a México, únicamente tuvieron que asentir y confirmar que la conjetura realizada por las autoridades norteamericanas era correcta.

Otros fueron deportados a México sin que hubiesen tenido que mentir respecto de su identidad. Como afirmaba un migrante guatemalteco: "Yo no les dije nada, ellos me agarraron y me deportaron a México" (David, 2012). Algunos fueron deportados a México porque les confundieron con mexicanos. Ellos mencionaban el término "pasar entre la bola" para hacer referencia a la forma en cómo se producen las deportaciones: con celeridad y sin tiempo para corroborar la nacionalidad de los deportados. Expresiones como "me deportaron a México entre toda la bola" (Adrián, 2011) o "me mandaron en la bola de los mexicanos" (Agustín, 2011) se repiten en algunas entrevistas.

Otros entrevistados no explicaban este tipo de deportaciones como una falta de cuidado o como resultado de la prisa en expulsar a los migrantes del país; sino como un acto deliberado por remover a México 
ciudadanos de otros países. Los siguientes ejemplos representan casos de migrantes que pensaban que serían enviados a sus países porque las autoridades conocían sus nacionalidades; pero fueron deportados a México:

[...] No les dije nada, ellos ya tenían mis datos, pero cuando estaban en el aeropuerto subiendo a la gente del avión a un autobús, para llevarlos a la frontera; como cuando me subieron allá en Houston me sentaron con unos mexicanos, así que al bajar me subieron con ellos al camión y no me dijeron nada y nos dejaron libres en el puente de McAllen (Texas), ya de ahí pasamos a Reynosa (Daniel, 2012).

[...] Vengo deportado de allá de Estados Unidos, de Alabama; allá estaba trabajando; pero me agarraron y me aventaron aquí por la ciudad de Matamoros [...] Ellos también están conscientes de que uno va a regresar a Estados Unidos porque allá está su familia; sí me preguntaron muchas cosas, y dije la verdad, no dije mentiras, les dije que desde los 10 años vivo allá y que allá tengo a mi familia, y que no tenía antecedentes [...]. Todos los que tenían para deportar eran mexicanos [...] Ellos sabían que era de El Ceibo, de Guatemala, yo les dije, no les quise decir mentiras (Diego, 2012).

Algunos argumentan que la deportación de migrantes centroamericanos a México obedece a la economicidad de este tipo de prácticas. Como afirmaba una migrante guatemalteca:

[...] Hay los que mienten, y a otros los deportan aquí a México para no gastar en mandarlos hasta su país, sí hay centroamericanos que son deportados sólo a este lado de la frontera con México, ellos tienen ventajas porque se vuelven a pasar para allá; pero traen desventajas porque los pueden agarrar los delincuentes y secuestrarlos (Teodora, 2013).

\section{El uso de documentos mexicanos apócrifos}

Los migrantes centroamericanos no compran documentos apócrifos únicamente para poder trabajar en Estados Unidos, sino también para transitar de forma más segura por México. Zarco Palacios (2013, p. 78) ha 
señalado que autoridades del Registro Civil y del IFE, en complicidad con delincuentes, expiden documentos apócrifos (actas de nacimiento y credenciales de elector) por las cuales se llegan a pagar hasta 3000 pesos. Como consecuencia, cuando los migrantes son detenidos por las autoridades estadunidenses, muestran los documentos que compraron en México para evitar ser deportados a sus países de origen.

Un migrante hondureño dijo que lo deportaron por Ciudad Juárez "por la credencial de elector que me dieron en Chiapas" (Bernardo, 2012). Asimismo, un migrante del mismo país señalaba que fue deportado por Piedras Negras "porque mis papeles eran de mexicano y traigo mi credencial de elector de mexicano, y según esto soy de Perote, Veracruz" (Agustín, 2011). Pero no todos los migrantes centroamericanos tienen credenciales de elector apócrifas; en algunos casos estas credenciales son legítimas. En México, sobre todo en las áreas rurales más remotas, un porcentaje importante de los niños no es registrado hasta años después de su nacimiento y algunos nunca son registrados. Esta circunstancia es aprovechada por algunas personas foráneas, que después de residir en México durante años logran obtener un acta de nacimiento manifestando que nacieron en el país pero nunca fueron registrados. Esto es lo que hizo el padre de un migrante salvadoreño. Él señalaba que

fueron a las autoridades y les dijo que pues éramos mexicanos, y pero que nunca se habían registrado, que porque nunca se las habían pedido para ningún trabajo [...] A todos nos dieron el acta y tenemos credencial de elector; pero somos del Salvador (Carmelo, 2012).

Por otra parte, las autoridades estadunidenses pueden distinguir cuando un documento de identidad es apócrifo; pero no cuestionan la nacionalidad del portador si no es estadunidense. Cuando un migrante de Centroamérica porta un documento perteneciente a alguien de nacionalidad mexicana, éste es deportado a México aunque las autoridades sepan que ésta podría no ser su verdadera nacionalidad. El caso de un migrante guatemalteco que usurpó la identidad de una persona de la ciudad de México resulta llamativo. Las autoridades estadunidenses conocían que el documento que portaba era apócrifo, por eso se lo retuvieron. Si hubiesen pensado que su identificación era genuina se la hubiesen 
devuelto; sin embargo, no cuestionaron su nacionalidad y lo deportaron a México:

[...] dije que era mexicano, ya no hablo como guatemalteco, he perdido el acento de allá (Guatemala); hablo más mejor el español y el inglés, y me mandaron a México porque cuando estaba trabajando allá, en California, tenía unos papeles falsos que me habían vendido; esos papeles eran de una persona de aquí, de la Ciudad de México, me los vendieron para que pudiera entrar a trabajar ahí, y como los traía, me identificaron de aquí; pero lo malo fue que no me los entregaron cuando me deportaron (Eladio, 2012).

\section{El pago de sobornos para ser deportados a México}

Algunos de los entrevistados dijeron que las autoridades estadunidenses les propusieron deportarles hasta México, en lugar de expulsarles hasta sus lugares de origen, a cambio del pago de un soborno. Sin embargo, únicamente uno de los entrevistados manifestó que había pagado un soborno para evitar ser deportado hasta su país. Lo que predomina en las entrevistas son los testimonios en tercera persona. Esto resta credibilidad a los mismos; aunque la repetición de estos testimonios manifiesta la existencia de un cierto grado de veracidad en los mismos.

Aceptar este tipo de sobornos constituye una práctica nociva y reprobable por tres razones: 1) aquellos inmigrantes centroamericanos deportados a alguna de las ciudades fronterizas mexicanas corren un riesgo elevado de ser reclutados por la delincuencia organizada; 2) la deportación de migrantes centroamericanos en ciudades fronterizas facilita su reingreso en Estados Unidos; y 3) esta práctica vulnera la soberanía nacional de México porque facilita la entrada en el país de personas que no pueden acreditar su estancia legal en México. Es difícil saber si se trata de sucesos aislados o de eventos de carácter más sistemático; pero los entrevistados dejan entrever que este tipo de prácticas ocurre con cierta frecuencia:

[...] A ellos [unos migrantes de El Salvador y Honduras] los deportaron porque según dijeron habían pagado para que los deportaran a México y no a donde eran (Eladio, 2012). 
Simón P. Izcara y Karla L. Andrade / Causas e impacto de la deportación de migrantes centroamericanos

[...] Te piden dinero para arreglarte y deportarte a México o dejarte allá en donde estás (Gonzalo, 2013).

[...] Si tienes dinero, sí te pueden deportar a México, aquí a la frontera norte, por eso hay muchos centroamericanos en la frontera, porque se paga y no te mandan a tu país (Heladio, 2013).

[...] Me dijeron que si quería que me deportaran a México tenía que pagar, pero no tenía dinero para pagar, los que tuvieron sí los hicieron pasar por mexicanos y los deportaron a la frontera de México (Paloma, 2012).

[...] Se les paga a los mismos migras que te van a deportar y los costos varían mucho dependiendo de las personas que hayan agarrado; si agarran a una mujer que trabaja en una fábrica seguro le cobran menos que a una prostituta (Rosario, 2012).

[...] Sí hay centroamericanos que son deportados a México, me imagino que a los que agarran pasando son a los que deportan a México otra vez, por ejemplo si me agarran a mi pasando no me van a deportar a Guatemala, me van a regresar al lado de México (Teodora, 2013).

Uno de los entrevistados hablaba del riesgo de intentar sobornar a las autoridades migratorias estadunidenses porque la mayor parte de los agentes no aceptaban sobornos. Aunque esta afirmación dejaba entrever que sí era posible sobornar a algunos agentes:

Sí hay personas que lo hacen; pero para hacerlo tienes que tener alguien que tenga dinero; para arreglar más fácil y que te manden a México hay que pagar si eres centroamericano, pagas una fuerte cantidad de dólares y no te mandan a Guatemala, te deportan a México, pero tienes que saber con quién haces trato, porque si le ofreces dinero a un migra que no es corrupto te manda a la cárcel, por eso muchos no hacen esto de pagar, porque como te puede ir bien, a lo mejor y te va mal (Genaro, 2013).

Por otra parte, el siguiente testimonio manifiesta que las autoridades migratorias estadunidenses conocen que aquellos migrantes centroamericanos 
deportados en la frontera presentan una elevada probabilidad de ser secuestrados por la delincuencia organizada y obligados a colaborar con ellos, lo que hace más reprobable este tipo de prácticas:

[...] Me trajeron de Arizona a Guatemala, me trajeron en avión, y acá me dejaron; decían que nos podían dejar en México, pero que no, porque éramos para hacer más fuerte a la delincuencia organizada, y mejor nos deportaron hasta acá, a Guatemala, y me dijeron: si quieres regresar, que te cueste, y si te agarramos de ilegal te vamos a llevar a la cárcel porque ya tenemos tus datos (Manuela, 2012).

\section{El efecto de las deportaciones de centroamericanos a México}

El principio de soberanía no tiene un carácter absoluto. El derecho internacional otorga al Estado la facultad para controlar el ingreso, la residencia y la expulsión de no ciudadanos; pero también reconoce los derechos humanos que los estados se comprometen a garantizar dentro de sus jurisdicciones (Mejía, 2011, p. 77). De este modo, el derecho internacional busca un equilibrio entre el interés legítimo de los Estados y los derechos fundamentales de los no ciudadanos sujetos a deportación.

Estados Unidos es un país reacio a firmar acuerdos internacionales que protejan los derechos humanos de los migrantes. La resistencia a ratificar la convención internacional sobre la protección de los derechos de todos los trabajadores migratorios y sus familias, de 1990 (ОНСHR), muestra su falta de interés en los derechos humanos de los migrantes (Lyon, 2010). Asimismo, aunque Estados Unidos es signatario de la Declaración Americana de Derechos y Deberes del Hombre, ${ }^{2}$ su nivel de compromiso es débil (Mejía, 2011, p. 81). ${ }^{3}$

\footnotetext{
${ }^{2}$ En lo relacionado con los procedimientos de deportación, la Declaración Americana reconoce el derecho a la protección de la familia y a un proceso justo.

${ }^{3}$ Paradójicamente, Estados Unidos ocupó una posición de liderazgo en la elaboración del Protocolo de Palermo del año 2000 (UnODC, 2004), y lidera el movimiento internacional en contra del reclutamiento, transporte y empleo mediante la fuerza, fraude o coerción para el propósito de servidumbre involuntaria, peonaje, cautiverio por
} 
El 20 de febrero de 2004, la Secretaría de Relaciones Exteriores (SRE) de México y el Departamento de Seguridad Nacional de Estados Unidos firmaron un Memorándum de Entendimiento que establece el procedimiento de repatriación consistente con el respeto a los derechos humanos. El artículo 3 establece una serie de medidas, como la designación de puntos mutuos de repatriación y recepción de migrantes en horarios específicos, la preservación de la unidad familiar durante las repatriaciones y la repatriación durante horas diurnas de personas incapacitadas, menores y otras personas vulnerables, con objeto de respetar los derechos humanos de los migrantes.

La tendencia de Estados Unidos a subrayar el principio de soberanía, y el derecho a tomar las acciones legales necesarias para proteger el bienestar general, le ha llevado a adoptar medidas unilaterales que soslayan los derechos fundamentales de los no ciudadanos.

La falta de apego de Estados Unidos a la Declaración Americana y al Memorándum binacional aparece reflejada en violaciones sistemáticas al debido proceso, la falta de protección a la familia, ${ }^{4}$ la falta de notificación en la repatriación de personas pertenecientes a grupos vulnerables, la falta de respeto a los horarios establecidos y la falta de voluntad para castigar los abusos cometidos por los agentes migratorios SRE, 2005). Uno de los aspectos más graves son las devoluciones unilaterales; es decir, la falta de

endeudamiento o esclavitud de los migrantes. El aparente cambio de actitud de Estados Unidos en la última década se debe a una desviación del derecho internacional en la colocación de la responsabilidad por la vulneración de los derechos humanos de los migrantes en la delincuencia organizada. Esto coloca a los Estados en el papel de víctimas y no como villanos (Gallagher, 2010, p. 2). En este sentido, la UnODC (2004) empodera a los Estados al promover políticas más estrictas de control fronterizo para proteger a los migrantes de la delincuencia organizada.

${ }^{4}$ Durante las deportaciones se transgrede el derecho a la información ya que: 1) los migrantes desconocen el contenido de los documentos que firman y no tienen acceso posterior a los mismos, por lo que desconocen las consecuencias legales de su expulsión: no saben si fue una salida voluntaria, deportación o remoción expedita; 2) los migrantes no tienen información sobre el lugar y la fecha de la repatriación; y 3) los migrantes víctimas de delitos graves no tienen información sobre los beneficios que pueden recibir. Por otra parte, la separación de los padres de sus hijos menores, resultado de los programas $287(\mathrm{~g})$ y Comunidades Seguras, o la repatriación de los miembros de la familia en distinta fecha por diferente lugar, resultado de las devoluciones laterales, vulnera los derechos de los menores (Del Ángel et al., 2013). 
notificación a los Consulados Mexicanos en la franja fronteriza sobre las deportaciones que Estados Unidos realiza. Esto provoca que las autoridades mexicanas no se encuentren preparadas para recibir y atender a las personas deportadas. Asimismo, la falta de verificación del Instituto Nacional de Migración de muchos de los deportados, impide que se tenga un control del lugar de origen de los migrantes y que se les pueda prestar ayuda. En conclusión, las deportaciones masivas unilaterales violan el Memorándum binacional porque desbordan la capacidad del Instituto Nacional de Migración (INM) para darles atención.

En los territorios fronterizos las repatriaciones han conducido a percepciones y prácticas de intolerancia hacia el extranjero o el nacional devuelto. El razonamiento es el siguiente: 1) los deportados con antecedentes penales presentan una tendencia a unirse a los grupos delictivos, y 2) los deportados sin antecedentes cometen delitos debido a la desesperación de encontrarse en una ciudad que no conocen. Estos argumentos han sido esgrimidos por autoridades fronterizas, como los alcaldes de Nogales o Ciudad Juárez. El alcalde de Ciudad Juárez en el año 2009 solicitó al gobierno estadunidense que no deportase indocumentados con antecedentes penales por esta ciudad fronteriza, ya que los migrantes deportados sumaban más de $10 \%$ de los muertos por enfrentamientos entre delincuentes (Alarcón y Becerra, 2012, p. 128). Aunque, como han señalado Alarcón y Becerra (2012, p. 144), muy pocos son criminales peligrosos, la mayor parte de los deportados cometieron ofensas menores.

Los datos del cuadro 5 parecen confirmar los temores de las autoridades fronterizas. Aparentemente, muchos de los migrantes centroamericanos deportados a las ciudades fronterizas mexicanas terminan en las filas de la delincuencia organizada. El $87 \%$ de los entrevistados deportados desde Estados Unidos hasta una ciudad fronteriza mexicana fue secuestrado por la delincuencia organizada y obligado a delinquir; mientras que en el caso de los que fueron deportados a Centroamérica y luego se internaron en México para retornar al país del norte, el porcentaje descendía al 20\%. Aunque casi la mitad de los entrevistados que atravesaban el país de sur a norte tuvo en algún momento un tipo de encuentro con la delincuencia organizada.

Es una simplificación señalar que los centroamericanos devueltos a México son captados por las redes delictivas, ya que estos datos provienen 
de una muestra intencional que sobrerrepresenta los casos de los migrantes centroamericanos afectados por la violencia. Fueron entrevistados migrantes que quedaron varados en el territorio mexicano. Los casos de éxito: aquellos migrantes que tienen recursos para pagar las tarifas cobradas por los "polleros" y cruzan el territorio mexicano sin percances, son más difíciles de contactar porque no deambulan libremente por las calles ni trabajan en lugares específicos: los "polleros" los resguardan en casas de seguridad y no permiten que hablen con extraños. ${ }^{5}$

Tener antecedentes penales ${ }^{6}$ o la desesperación de encontrarse en una ciudad desconocida no lleva a los migrantes centroamericanos a unirse a los grupos delictivos. Aquellos que terminan en las filas de la delincuencia organizada son generalmente víctimas de trata. Para que exista trata deben darse tres elementos: la acción, el medio y el propósito. Los dos primeros elementos forman el actus reus del delito de trata y el último elemento el mens rea. La acción hace referencia al reclutamiento; el medio implica la fuerza, la coerción o el engaño, y el propósito aparece relacionado con la explotación (Gallagher, 2010, p. 29 y ss.).

Únicamente cuatro de los 30 migrantes centroamericanos que se involucraron con la delincuencia organizada fueron reclutados sin violencia, el resto decidieron cooperar con los delincuentes después de días o semanas de tortura. La violencia a la que fueron sometidos los entrevistados para lograr que se incorporasen a las organizaciones delictivas aparece reflejada en los siguientes testimonios:

Me agarraron, me dijeron que estaba secuestrada, que les diera información de mi familia para que pagaran por mí, pero no les dije nada porque a una

${ }^{5}$ Los migrantes centroamericanos deportados a las ciudades fronterizas mexicanas y que cuentan con la ayuda económica de sus familiares o empleadores, vuelven a cruzar a Estados Unidos en unos pocos días. Por otra parte, si hubiésemos realizado las entrevistas en las casas de acogida a los migrantes ubicadas en la frontera, en lugar de hacerlas en espacios públicos o en los lugares de trabajo de los migrantes, los datos obtenidos hubiesen sido diferentes. En este caso el grado de involucramiento con la delincuencia organizada de los migrantes centroamericanos deportados a México hubiese sido bajo o nulo, ya que aquí son acogidos por unos días tras la deportación. ${ }^{6}$ Quince de los entrevistados (12 hombres y 3 mujeres) tenían antecedentes penales en Estados Unidos por delitos de robo, consumo/posesión de drogas, uso de papeles falsos, delitos de tráfico vial, violencia doméstica o fraude. 


\section{Cuadro 5. Lugar de deportación de los migrantes entrevistados y grado de involucramiento con la delincuencia organizada}

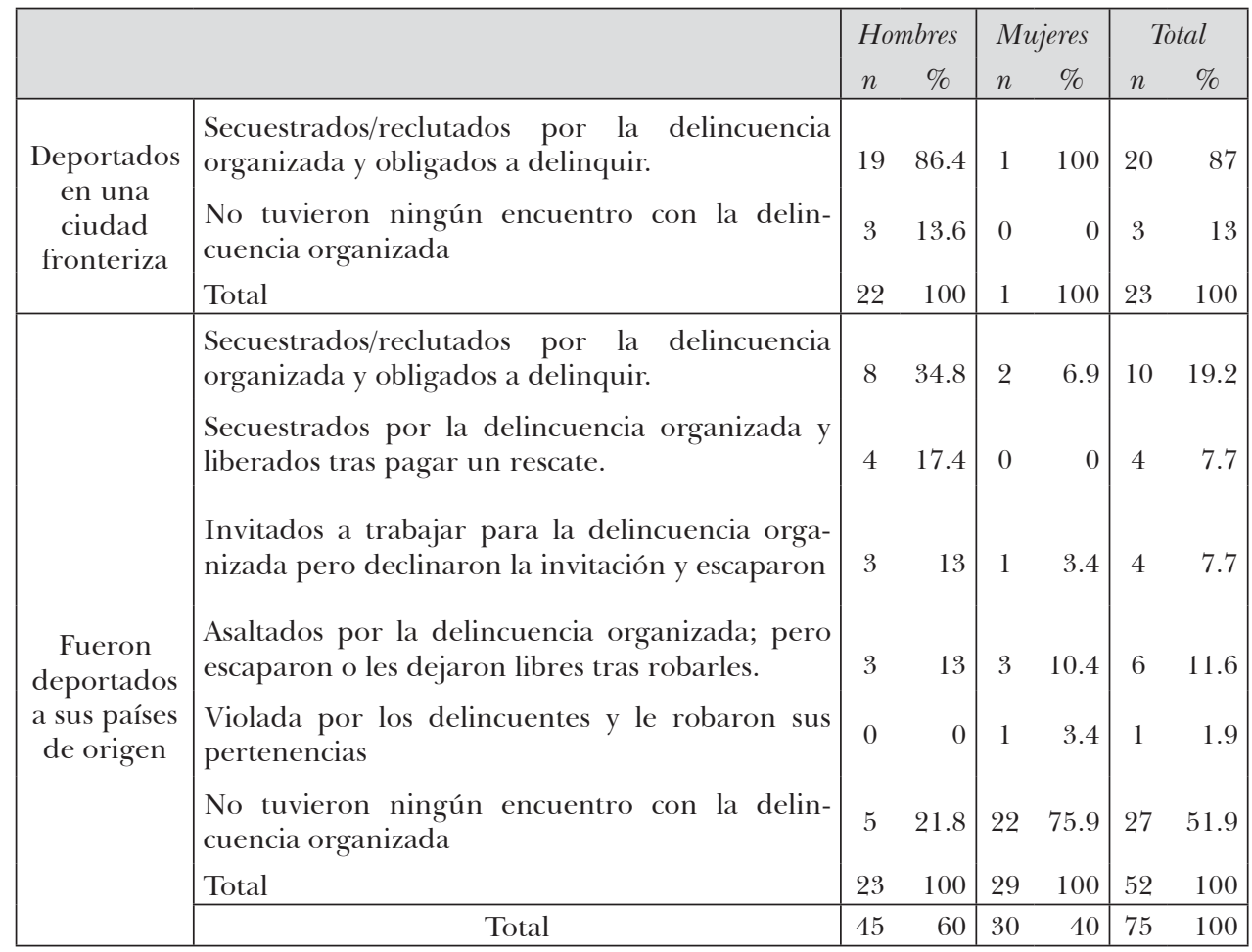

Fuente: Elaboración propia.

persona que estaba ahí ya habían pagado por ella y al último no la entregaron, y la mataron, por eso pensé, qué caso tiene que gasten en mí, para qué si me van matar, eso era lo que pensaba; pero pasaron los días y entre ellos había un jefe de cargo, era el que mandaba, y le gusté y me dijo que iba a trabajar con él [...] Abusaron sexual y psicológicamente, me amenazaban, me echaban miedo para que quisiera trabajar con ellos (Silvia, 2012).

Me tenían tan amenazada, cada que querían abusaban de mí [...] Yo andaba ahí ayudando en todo lo que me pedían hacer, o había veces que me quedaba cuidando gente secuestrada en casas de seguridad [...] Ellos tienen gente en 
todos los lados, por eso yo les tengo mucho miedo y sé que si me voy me van a encontrar o van hacerle algo a mis hijos (Sara, 2012).

Salimos de ahí, de la casa [del Migrante], y un grupo de gente armada nos levantó de la plaza y nos llevaron a un rancho, y ahí nos tuvieron cautivos y nos pidieron dinero, o si queríamos estar vivos, que íbamos a trabajar para ellos, y pues, no nos quedó de otra más que aceptar a trabajar con ellos; pero casi todos los días nos golpeaban con unas tablas (Adrián, 2011).

Yo trabajé con ellos; pero me hicieron a la fuerza que trabajara, me amenazaban con matar a mi familia, me decían que ellos sabían todo sobre mi familia [...] Me golpeaban, me maltrataban mucho, tengo huellas de las cosas malas que me hacían (Gilberto, 2013).

Me dejaban los golpes marcados; eso era todos los días, casi por un mes, hasta que acepté bien trabajar con ellos (Germán, 2013).

Casi todos los entrevistados relataban experiencias similares y describían su experiencia con los grupos delictivos como una situación de esclavitud. Los entrevistados trabajaron para la delincuencia organizada durante un periodo que se extendió de tres meses a más de seis años, pero sólo algunos recibieron un salario por realizar actividades que incluían el cobro de extorsiones, el robo y asalto en carreteras, el secuestro, el halconaje, el sicariato, etc. Además, ninguno recibía el dinero o los bienes incautados en las extorsiones, robos o secuestros. Esto era acaparado por personas con posiciones superiores en la organización. Aquellos que insinuaban la idea de tomar parte de este dinero eran castigados de modo severo.

Yo trabajo por un salario, yo no recibo ningún centavo de las cuotas, yo soy cobrador y entrego el dinero a un superior [...] Una vez hice un comentario, nomás así de juego, que llevábamos un montón de dinero, y cuando llegué me castigaron, me dieron una tamboriza y me tuvieron encerrado como una semana, y bien golpeado (Isidro, 2013).

El carácter de víctima de los entrevistados se refleja en el hecho de que 22 huyeron de la organización delictiva y 7 deseaban abandonar la 
organización; pero no se atrevían porque temían por su vida y la de sus familias. Solamente un migrante guatemalteco deportado en 2010 a Nuevo Laredo se encontraba a gusto en la organización delictiva de la que formaba parte. Tras ser deportado, los primeros tres días los pasó en la Casa del Migrante, y después encontró un trabajo como lavacoches; pero fue secuestrado por error y terminó trabajando para un grupo delictivo. En el momento de la entrevista, tras dos años de trabajo para la delincuencia organizada robando automóviles y cajeros automáticos, ya no deseaba dejar este tipo de vida:

Yo aquí estoy bien a todo dar con viejas buenas [.... Yo estaba limpiando y me levantaron a puras patadas, yo me asusté, no sabía nada, ni por qué me levantaban ni nada, me llevaron por error, y luego, ya que vino otra persona, les dijo que yo no era, y luego me dijeron: mira, si quieres que te perdonemos la vida vas a trabajar para nosotros, y yo acepté porque ya la estaba pasando mal limpiando coches, porque no sacaba nada y tenía que pagar por trabajar, y pues, empecé a trabajar con ellos (Fernando, 2010).

El caso de Fernando es el único donde no puede hablarse de trata, ya que esta persona, aunque fue secuestrada con violencia, aceptó rápidamente el trabajo que le ofrecían y deseaba seguir delinquiendo. En el resto de los casos estudiados sí existió trata. Aunque los entrevistados cometieron delitos muy graves, lo hicieron bajo coacción. En estos casos el derecho internacional señala que no debe culparse a las personas víctimas de trata por los actos cometidos como resultado de esta situación. Hay dos modelos legales bajo los cuales pueden no perseguirse estos delitos: el modelo de "causalidad" y el modelo de "coacción". El primero contempla el delito como un resultado de la situación de trata; el segundo contempla el delito como un acto coaccionado (Gallagher, 2010, p. 284).

Los resultados de esta investigación indican que los encuentros con la delincuencia de los migrantes deportados hasta sus países de origen son menores y menos violentos que los de aquellos que son deportados en la frontera mexicana. Los últimos son generalmente obligados a delinquir cuando son secuestrados, mientras que los primeros es más probable que sean secuestrados para exigir el pago de un rescate, o simplemente les roban sus pertenencias y les dejan libres. Esto tiene una explicación lógica. 
Los migrantes deportados carecen de recursos económicos, generalmente son expulsados con las manos vacías. Además, en los territorios fronterizos las luchas por el territorio y contra las fuerzas de seguridad del Estado son más encarnizadas, por lo que allí la necesidad de reclutar nuevos miembros es más apremiante. Por lo tanto, la mayor utilidad que tienen para los grupos delictivos los migrantes deportados en las ciudades fronterizas es integrarles a estas organizaciones. Por el contrario, los migrantes en tránsito por México que se dirigen a Estados Unidos casi siempre tienen dinero, ya que el costo de llegar al país del norte es muy elevado. Si no tuviesen recursos económicos, ni contasen con amigos, familiares o un antiguo empleador dispuestos a pagarles una parte del costo de emigrar, es poco probable que se hubiesen aventurado a salir de su país.

\section{El caso de Javier}

El caso de Javier, un migrante guatemalteco de 34 años de edad, ejemplifica cómo el pago de sobornos para remover migrantes centroamericanos a México coloca a éstos en una situación de alto riesgo. Javier decidió emigrar a Estados Unidos en enero del 2000 porque su familia perdió las tierras y no tenía dinero para mantener a sus dos hijos, de uno y dos años de edad. Esta experiencia fue traumática; tras pasar el río Suchiate, donde casi se ahoga, su grupo fue asaltado por delincuentes, que les robaron lo que tenían, les golpearon, y a las mujeres más jóvenes las violaron. Llegó a Arkansas en febrero de 2002, donde comenzó a trabajar como peón agrícola y con los años ascendió al puesto de capataz, teniendo a su cargo a 80 trabajadores indocumentados. Sin embargo, en febrero de 2013 fue deportado por dar empleo a varias personas que huían de la policía.

Debido a su experiencia anterior, "ya no quise arriesgarme a que me volvieran a Guatemala y tener que venirme de nuevo, porque necesito trabajar; mejor pagué allá en Arkansas a la migra y me pasé por mexicano". Su patrón quiso impedir que lo deportasen porque lo necesitaba en el rancho, pero únicamente pudo negociar que le removiesen a México. La idea de ser deportado a la frontera mexicana, según Javier, surgió de su patrón. 
El patrón mío me dio la idea de que no me deportaran a Guatemala sino a México, para regresarme a Arkansas a trabajar. Esa fue idea del patrón, porque yo no sabía de eso; el patrón pagó y me pasaron por mexicano, por eso mismo yo no me regresé a Guatemala, y el patrón quiso ayudarme porque le he platicado que me fue muy difícil llegar a Estados Unidos (Javier, 2013).

Javier dijo que su patrón pagó "cinco mil dólares, eso fue lo que dio a la migra para que me deportaran como mexicano”. Sin embargo, no tuvo suerte. Nada más cruzar el puente internacional que une Brownsville con Matamoros fue secuestrado por la delincuencia organizada. Como él decía: "Si yo hubiera sabido que me iba a pasar todo esto, mejor me hubieran deportado a Guatemala; pero claro, no fue problema del patrón, no sabíamos lo que me iba a pasar en México”. Los próximos cien días fueron un cautiverio. Sus captores no pidieron un rescate por él porque "a ellos no les importaba que pagaran por mí, a ellos les importaba tenerme trabajando". Después de ser torturado aceptó trabajar para la delincuencia organizada, primero en Tamaulipas y más tarde en un campo de entrenamiento en la sierra de Chiapas. Todo este tiempo buscó la oportunidad de escapar, hasta que la encontró un día de lluvia torrencial, porque

[...] ahí donde estábamos en la sierra había una bajada de agua muy correntosa, pero mucha agua que bajaba hacia un arroyo, y cuando estaba bajando mucho agua, por ahí me aventé, y el agua me trajo más debajo de la sierra; así fue como me escapé, como estaba lloviendo mucho no se dieron cuenta.

En el momento de la entrevista Javier se encontraba en una localidad del sudoeste de Chiapas; no tenía dinero, pero estaba esperando a la Bestia para avanzar hacia el norte y pedir ayuda a su patrón. Él decía que "pudiendo hablarle al patrón, le hablo, y me va ayudar para irme de aquí a Estados Unidos, y más me ayudará con lo que me ha pasado, aquí corre peligro mi vida”. Regresar a Guatemala no era una opción, ya que los delincuentes sabían dónde vivía su familia, y si él regresase no sólo pondría en peligro su vida, sino también la de su familia. Él decía que su única oportunidad de supervivencia era llegar a Estados Unidos con la ayuda de su patrón. 
Simón P. Izcara y Karla L. Andrade / Causas e impacto de la deportación de migrantes centroamericanos

\section{Conclusiones}

La mayor parte de las deportaciones de migrantes centroamericanos a México obedece al engaño; se trata de personas que mienten sobre su identidad. En estos casos las autoridades estadunidenses no encuentran otra opción que removerles a México, ya que es difícil verificar la nacionalidad de una persona que no tiene ningún documento de identidad. Pero el hecho de que muchos de los entrevistados mencionasen que las autoridades estadunidenses aceptaban sobornos por deportarles a México en lugar de removerles hasta sus países de origen, resulta inquietante porque vulnera la soberanía nacional de México, facilita el retorno subrepticio de los migrantes a Estados Unidos y les expone a niveles elevados de violencia.

La repetición de la idea de que es posible sobornar a algunos agentes migratorios estadunidenses para evitar ser removidos hasta sus países de origen da un cierto grado de credibilidad a estos relatos. Sin embargo, los entrevistados solían hablar de esta situación en tercera persona: conocían a otras personas que les habían dicho que ellos habían pagado un soborno para ser deportados a México — sólo uno de los entrevistados se expresó en primera persona. Por lo tanto, estas afirmaciones que hablan de corrupción de las autoridades estadunidenses deben ser consideradas con cautela, pero deben ser estudiadas con mayor profundidad.

La deportación de migrantes centroamericanos de Estados Unidos a México renueva las filas de la delincuencia organizada porque muchos son secuestrados y obligados a delinquir. Esto acrecienta el problema de la violencia que padecen los estados fronterizos. Pero la incorporación de los migrantes centroamericanos a los grupos delictivos se realiza generalmente bajo coacción. Muchos de los migrantes centroamericanos que se han unido a la delincuencia organizada son víctimas de trata, ya que fueron reclutados con violencia y esclavizados.

El artículo 78 de la Ley General para Prevenir, Sancionar y Erradicar los delitos en Materia de Trata de personas y para la protección y asistencia a las víctimas de estos delitos (2012) contempla el otorgamiento de visas por razones humanitarias a las víctimas de trata extranjeras, y el artículo 81 contempla el establecimiento de un fondo para la protección y asistencia a las víctimas. En este sentido, la asistencia a los migrantes que son víctimas de las organizaciones delictivas podría debilitar a la delincuencia 
organizada. Si los migrantes tuviesen la certeza de que los delitos que cometieron serían considerados como resultado de una situación de trata o como actos coaccionados y contasen con la protección de las autoridades, muchos abandonarían las organizaciones para las que trabajan.

\section{Bibliografía}

Alarcón, R. y Becerra, W. (2012). ¿Criminales o víctimas? La deportación de migrantes mexicanos de Estados Unidos a Tijuana, Baja California. Norteamérica, 7(1), 125-148.

Aberson, D. F. (1974). Deportations of aliens for criminal convictions. Pepperdine Law Review, 2(52), 52-82.

Blanchard, S., Hamilton, E. R., Rodríguez, N. y Yoshioka, H. (2011). Shifting trends in Central American migration: A demographic examination of increasing Honduran-U.S. immigration and deportation. The Latin Americanist, 55(4), 61-84.

Borjas, G. J. (1994). The economics of immigration. Journal of Economic Literature, $32,1667-1717$.

Borjas, G. J. (2003). The labor demand curve is downward sloping: Reexamining the impact of immigration on the labor market. The Quarterly Journal of Economics, 118(4), 1335-1374.

Borjas, G. J. (2006). Immigrants in, wages down. How to do the figuring. National Review, 58(8), 40-42.

Brabeck, K. M., Lykes, M. B. y Hershberg, R. (2011). Framing immigration to and deportation from the United States: Guatemalan and Salvadoran families make meaning of their experiences. Community, Work and Family, 14(3), 275-296.

Casillas, R. (2011). The dark side of globalized migration: The rise and peak of criminal networks. The case of Central Americans in Mexico. Globalizations, $8(3), 295-310$.

Champlin, D. (2010). Institutionalist perspectives on immigration policy: An update. Journal of Economic Issues, 44(2), 301-312.

Chiswick, B. R. (1988). Illegal Immigration and Immigration Control. The Journal of Economic Perspectives, 2(3), 101-115.

De León, J. (2013). The efficacy and impact of the alien transfer exit programme: Migrant perspectives from Nogales, Sonora, Mexico. International Migration, 51(2), 10-23.

Del Ángel, P., Flores, E., Martínez, L., Moreno, J., Navarrete, B. y Siu, E. (2013). Segundo Informe: Violaciones a derechos humanos de personas migrantes mexicanas 
Simón P. Izcara y Karla L. Andrade / Causas e impacto de la deportación de migrantes centroamericanos

detenidas en los Estados Unidos 2011-2012. México: Programa de Defensa e Incidencia Binacional.

Department of Homeland Security. (2011). 2011 Yearbook of Immigration Statistics. Recuperado de <http://www.dhs.gov/sites/default/files/publications/immigration-statistics/yearbook/2011/ois_yb_2011.pdf>

Escobar, M. (2011). Irrecuperable border subjects: Imprisoned Latina migrants and the added difficulties of accessing parole. En J. Akers y E. Davalos (Eds.), Wounded Border. Readings on the Tijuana/San Diego Region and Beyond (pp. 7991). San Diego: City Works Press,.

Galbraith, J. K. (1979). The Nature of Mass Poverty. Cambridge: Harvard University Press.

Gallagher, A. T. (2010). The International Law of Human Trafficking. New York: Cambridge University Press.

Gordon, W. (1975). A case for a less restrictive border policy. Social Science Quarterly, 56(3), 485-491.

Hagan, J., Eschbach, K. y Rodríguez, N. (2008). US deportation policy, family separation, and circular migration. The International Migration Review, 42(1), 64-88.

Hagan, J., Castro, B. y Rodríguez, N. (2010). The effects of U.S. deportation policies on immigrant families and communities: Cross-border perspectives. North Carolina Law Review, 88, 1799-1824.

Hagan, J., Rodríguez, N. y Castro, B. (2011). Social effects of mass deportations by the United States government, 2000-10. Ethnic and Racial Studies, 34(8), 1374-1391.

Hernández, K. L. (2010). Migra! A History of the U. S. Border Patrol. Los Angeles: University of California Press.

Izcara, S. P. (2010a). Los factores no salariales en la migración internacional: el caso tamaulipeco. Revista de Ciencias Sociales, 16(4), 605-615.

Izcara, S. P. (2010b). Redes migratorias o privación relativa: La etiología de la emigración tamaulipeca a través del programa H-2A. Relaciones, 31(122), 245278.

Izcara, S. P. (2014). Manual de investigación cualitativa. México: Fontamara.

King, D. S. y Smith, R. M. (2005). Racial orders in American political development. American Political Science Review, 99(1), 75-92.

Ley general para prevenir, sancionar y erradicar los delitos en materia de trata de personas y para la protección y asistencia a las víctimas de estos delitos. (2012). Diario Oficial de la Federación.

Lyon, B. (2010). The unsigned United Nations migrant worker rights convention: An overlooked opportunity to change the "Brown collar" migration paradigm. International Law and Politics, 42, 389-500. 
Mejía, J. A. (2011). Migrantes deportados: Entre la concepción de los desechos humanos y la de los derechos humanos. Encuentro, 88, 72-85.

Menjívar, C. y Abrego, L. J. (2012). Legal violence: Immigration law and the lives of Central American immigrants. American Journal of Sociology, 117(5), 13801421.

Piore, M. J. (1979). Birds of Passage: Migrant Labour and Industrial Societies. Cambridge: Cambridge University Press.

Rosenblum, M. R. (2012). Border Security: Immigration Enforcement between Ports of Entry. Congressional Research Service report for Congress. Federal Publications. (Paper 878). Recuperado de: < http://digitalcommons.ilr.cornell. edu/cgi/viewcontent.cgi?article $=1883 \&$ context $=$ key_workplace $>$

Secretaría de Relaciones Exteriores. (Diciembre, 2005). Mecanismos de Repatriación entre agencias federales de EE.UU. y México. Duodécimo Foro Legislativo, El Paso, Texas.

Shaw, I. F. (2003). La evaluación cualitativa. Introducción a los métodos cualitativos. Barcelona: Paidós Básica.

United Nations High Commissioner for Human Rights (OHCHR). (1990). International Convention on the protection of the rights of all migrant workers and members of their families adopted by General Assembly resolution 45/158 of 18 December 1990. Recuperado de: <http://www2.ohchr.org/english/bodies/cmw/ cmw.htm>

United Nations Office on Drugs and Crime (unODC). (2004). Protocol to Prevent, Suppress and Punish Trafficking in Persons, Especially Women and Children, supplementing the United Nations Convention against Transnational Organized Crime adopted by General Assembly resolution 55/25 of 15 November 2000. Recuperado de: $<$ https://www.unodc.org/documents/middleeastandnorthafrica//organised-crime/ UNITED_NATIONS_CONVENTION_AGAINST_TRANSNATIONAL_ ORGANIZ̄ED_CRIME_AND_THE_PROTOTOCOLS_THERETO.pdf $>$

Wainer, A. (2012). Exchanging people for money: Remittances and repatriation in Central America. Bread for the World Institute Briefing Paper, 18, 1-18.

Zarco, D. (2013). Analogía y problemática de la migración femenina centroamericana. En I. García y A. Munguía (Eds.), Migraciones globales. Experiencias regionales y enseñanzas para México (pp. 61-84). México: Jorale. 


\section{Anexo 1. Entrevistas citadas en el texto}

\begin{tabular}{|c|c|}
\hline Adrián & $\begin{array}{l}\text { Entrevista realizada en mayo de } 2011 \text { en Guémez (Tamaulipas) a un inmigrante } \\
\text { guatemalteco de } 36 \text { años de edad deportado a Piedras Negras (Coahuila) en } \\
2009 \text {. }\end{array}$ \\
\hline Agustín & $\begin{array}{l}\text { Entrevista realizada en mayo de } 2011 \text { en Guémez (Tamaulipas) a un inmigrante } \\
\text { hondureño de } 37 \text { años de edad deportado a Piedras Negras (Coahuila) en } 2009 .\end{array}$ \\
\hline Alberto & $\begin{array}{l}\text { Entrevista realizada en agosto de } 2011 \text { en Abasolo (Tamaulipas) a un inmigrante } \\
\text { guatemalteco de } 36 \text { años de edad deportado a Nuevo Laredo (Tamaulipas) en } \\
2008 .\end{array}$ \\
\hline Alfredo & $\begin{array}{l}\text { Entrevista realizada en agosto de } 2011 \text { en Padilla (Tamaulipas) a un inmigrante } \\
\text { hondureño de } 35 \text { años de edad deportado a Matamoros (Tamaulipas) en } 2010 .\end{array}$ \\
\hline Basilio & $\begin{array}{l}\text { Entrevista realizada en julio de } 2012 \text { en Hidalgo (Tamaulipas) a un inmigrante } \\
\text { hondureño de } 34 \text { años de edad deportado a Nuevo Laredo (Tamaulipas) en } \\
2008 .\end{array}$ \\
\hline Bernardo & $\begin{array}{l}\text { Entrevista realizada en julio de } 2012 \text { en Abasolo (Tamaulipas) a un inmigrante } \\
\text { hondureño de } 32 \text { años de edad deportado a Ciudad Juárez (Chihuahua) en } 2009 .\end{array}$ \\
\hline Carmelo & $\begin{array}{l}\text { Entrevista realizada en julio de } 2012 \text { en Hidalgo (Tamaulipas) a un inmigrante } \\
\text { salvadoreño de } 36 \text { años de edad deportado a Nuevo Laredo (Tamaulipas) en } \\
2008 \text {. }\end{array}$ \\
\hline Cirilo & $\begin{array}{l}\text { Entrevista realizada en julio de } 2012 \text { en San Fernando (Tamaulipas) a un } \\
\text { inmigrante hondureño de } 33 \text { años de edad deportado a Matamoros (Tamaulipas) } \\
\text { en } 2004 .\end{array}$ \\
\hline Daniel & $\begin{array}{l}\text { Entrevista realizada en agosto de } 2012 \text { en San Carlos (Tamaulipas) a un } \\
\text { inmigrante guatemalteco de } 38 \text { años de edad deportado a Reynosa (Tamaulipas) } \\
\text { en } 2011 \text {. }\end{array}$ \\
\hline David & $\begin{array}{l}\text { Entrevista realizada en agosto de } 2012 \text { en San Nicolás (Tamaulipas) a un inmigrante } \\
\text { guatemalteco de } 40 \text { años de edad deportado a Matamoros (Tamaulipas) en } 2011 .\end{array}$ \\
\hline Diego & $\begin{array}{l}\text { Entrevista realizada en septiembre de } 2012 \text { en Guémez (Tamaulipas) a } \\
\text { un inmigrante guatemalteco de } 20 \text { años de edad deportado a Matamoros } \\
\text { (Tamaulipas) en } 2012 \text {. }\end{array}$ \\
\hline Eduardo & $\begin{array}{l}\text { Entrevista realizada en septiembre de } 2012 \text { en Ciudad Victoria (Tamaulipas) a } \\
\text { un inmigrante guatemalteco de } 39 \text { años de edad deportado a su país en } 2012 \text {. }\end{array}$ \\
\hline Eladio & $\begin{array}{l}\text { Entrevista realizada en septiembre de } 2012 \text { en México D.F. a un inmigrante } \\
\text { guatemalteco de } 38 \text { años de edad deportado a Ciudad Juárez (Chihuahua) en } \\
2011 \text {. }\end{array}$ \\
\hline Felipe & $\begin{array}{l}\text { Entrevista realizada en octubre de } 2012 \text { en Monterrey (Nuevo León) a un } \\
\text { inmigrante guatemalteco de } 35 \text { años de edad deportado a Reynosa (Tamaulipas) } \\
\text { en } 2011 \text {. }\end{array}$ \\
\hline Fernando & $\begin{array}{l}\text { Entrevista realizada en octubre de } 2012 \text { en Monterrey (Nuevo León) a un } \\
\text { inmigrante guatemalteco de } 34 \text { años de edad deportado a Nuevo Laredo } \\
\text { (Tamaulipas) en } 2010 \text {. }\end{array}$ \\
\hline
\end{tabular}




\begin{tabular}{|c|c|}
\hline Genaro & $\begin{array}{l}\text { Entrevista realizada en enero de } 2013 \text { en El Mante (Tamaulipas) a un inmigrante } \\
\text { guatemalteco de } 35 \text { años de edad deportado a su país en } 2011 \text {. }\end{array}$ \\
\hline Germán & $\begin{array}{l}\text { Entrevista realizada en febrero de } 2013 \text { en Tampico (Tamaulipas) a un inmigrante } \\
\text { guatemalteco de } 28 \text { años de edad deportado a su país en } 2011 .\end{array}$ \\
\hline Gilberto & $\begin{array}{l}\text { Entrevista realizada en febrero de } 2013 \text { en Tampico (Tamaulipas) a un inmigrante } \\
\text { hondureño de } 27 \text { años de edad deportado a su país en } 2011 \text {. }\end{array}$ \\
\hline Gonzalo & $\begin{array}{l}\text { Entrevista realizada en marzo de } 2013 \text { en Tultitlán (Estado de México) a un } \\
\text { inmigrante salvadoreño de } 30 \text { años de edad deportado a su país en } 2012 .\end{array}$ \\
\hline Heladio & $\begin{array}{l}\text { Entrevista realizada en marzo de } 2013 \text { en México D.F. a un inmigrante } \\
\text { guatemalteco de } 25 \text { años de edad deportado a su país en } 2012 \text {. }\end{array}$ \\
\hline Ignacio & $\begin{array}{l}\text { Entrevista realizada en abril de } 2013 \text { en Ciudad Victoria (Tamaulipas) a un } \\
\text { inmigrante salvadoreño de } 27 \text { años de edad deportado a Reynosa (Tamaulipas) } \\
\text { en } 2012 \text {. }\end{array}$ \\
\hline Isidro & $\begin{array}{l}\text { Entrevista realizada en mayo de } 2013 \text { en Tijuana (Baja California) a un inmigrante } \\
\text { guatemalteco de } 37 \text { años de edad deportado a esta ciudad en } 2012 .\end{array}$ \\
\hline Javier & $\begin{array}{l}\text { Entrevista realizada en mayo de } 2013 \text { en Arriaga (Chiapas) a un inmigrante } \\
\text { hondureño de } 34 \text { años de edad deportado a Matamoros (Tamaulipas) en } 2013 .\end{array}$ \\
\hline Laura & $\begin{array}{l}\text { Entrevista realizada en septiembre de } 2012 \text { en México D.F. a una inmigrante } \\
\text { guatemalteca de } 38 \text { años de edad deportada a su país en } 2012 \text {. }\end{array}$ \\
\hline Manuela & $\begin{array}{l}\text { Entrevista realizada en septiembre de } 2012 \text { en México D.F. a una inmigrante } \\
\text { guatemalteca de } 30 \text { años de edad deportada a su país en } 2012 \text {. }\end{array}$ \\
\hline Paloma & $\begin{array}{l}\text { Entrevista realizada en septiembre de } 2012 \text { en México D.F. a una inmigrante } \\
\text { guatemalteca de } 24 \text { años de edad deportada a su país en } 2011 \text {. }\end{array}$ \\
\hline Rosario & $\begin{array}{l}\text { Entrevista realizada en septiembre de } 2012 \text { en México D.F. a una inmigrante } \\
\text { guatemalteca de } 30 \text { años de edad deportada a su país en } 2011 \text {. }\end{array}$ \\
\hline Sara & $\begin{array}{l}\text { Entrevista realizada en octubre de } 2012 \text { en Monterrey (Nuevo León) a una } \\
\text { inmigrante guatemalteca de } 37 \text { años de edad deportada a Nuevo Laredo } \\
\text { (Tamaulipas) en } 2011 \text {. }\end{array}$ \\
\hline Silvia & $\begin{array}{l}\text { Entrevista realizada en noviembre de } 2012 \text { en San Luis Potosí a una inmigrante } \\
\text { salvadoreña de } 31 \text { años de edad deportada a su país en } 2011 \text {. }\end{array}$ \\
\hline Teodora & $\begin{array}{l}\text { Entrevista realizada en enero de } 2013 \text { en El Mante (Tamaulipas) a una inmigrante } \\
\text { guatemalteca de } 26 \text { años de edad deportada a su país en } 2011 \text {. }\end{array}$ \\
\hline Vicenta & $\begin{array}{l}\text { Entrevista realizada en enero de } 2013 \text { en Tampico (Tamaulipas) a una inmigrante } \\
\text { guatemalteca de } 25 \text { años de edad deportada a su país en } 2012 \text {. }\end{array}$ \\
\hline
\end{tabular}

